\title{
The Evolutionary Game Analysis of Multiple Stakeholders in the Low-Carbon Agricultural Innovation Diffusion
}

\author{
Lixia Liu $\left(\mathbb{D},{ }^{1}\right.$ Yuchao Zhu, ${ }^{1}$ and Shubing Guo ${ }^{2}{ }^{2}$ \\ ${ }^{1}$ School of Economics, Tianjin University of Commerce, Tianjin 300134, China \\ ${ }^{2}$ College of Management and Economics, Tianjin University, Tianjin 300072, China \\ Correspondence should be addressed to Lixia Liu; liulixia77@163.com and Shubing Guo; sbguo20160831@126.com
}

Received 20 September 2019; Revised 12 December 2019; Accepted 27 January 2020; Published 22 February 2020

Academic Editor: Yan-Ling Wei

Copyright $($ C 2020 Lixia Liu et al. This is an open access article distributed under the Creative Commons Attribution License, which permits unrestricted use, distribution, and reproduction in any medium, provided the original work is properly cited.

Encouraging the adoption and diffusion of low-carbon agricultural technology innovation is an important measure to cope with climate change, reduce environmental pollution, and achieve sustainable agricultural development. Based on evolutionary game theory, this paper establishes a game model among agricultural enterprises, government, and farmers and analyzes the dynamic evolutionary process and evolutionary stable strategies of the major stakeholders. The impact of innovation subsidies, carbon taxes, and adoption subsidies on low-carbon agricultural innovation diffusion is simulated using Matlab software. The results show that the government's reasonable subsidies and carbon taxes for agricultural enterprises and farmers can increase the enthusiasm of agricultural enterprises and farmers to participate in low-carbon agriculture. This study can be used as a basis for the government to formulate more targeted policies to promote the diffusion of low-carbon agricultural innovation.

\section{Introduction}

With the rapid development of the global economy, global warming has become an issue of great concern to the international community. According to the IPCC's fifth assessment report, excessive carbon dioxide emission from human activities is the leading cause of climate warming [1]. For a long time, governments have been developing lowcarbon economy with practical actions and taking the second and third industries as key sectors of carbon emission management [2]. In recent years, with the acceleration of agricultural modernization, the impact of agriculture on global climate change is increasing. According to statistics, agriculture directly contributes $10 \%-12 \%$ of global greenhouse gas emissions $[3,4]$. Low-carbon agriculture is a new development mode featuring low energy consumption, low emission, and low pollution. The development of low carbon agriculture is the inevitable choice to realize the sustainable development of agriculture [5].

Research and development, promotion, and application of low-carbon agricultural technologies are the key measures to achieve carbon sequestration and emission reduction in agricultural production [6]. In recent years, many countries have adopted policies to stimulate the innovation and diffusion of low-carbon agricultural technologies, such as subsidies, tax incentives, and public loans [7-12]. However, the diffusion of low-carbon agricultural technologies is still slow, especially in developing countries. This situation is mainly due to the following two reasons. First, as demanders of low-carbon agricultural technologies, farmers are not enthusiastic about adopting low-carbon agricultural technologies affected by their knowledge level, income level, land size, and external environment [7-11]. Second, as providers of low-carbon agricultural means of production and technical services, agricultural enterprises are less motivated in low-carbon innovation due to the long cycle, high cost, and high-risk characteristics of low-carbon agricultural technology innovation [12]. Therefore, the obstacles to lowcarbon agricultural technology innovation and technology promotion and the implementation effect of the government's low-carbon agricultural policy have attracted much attention [11-15].

Although the importance and value of low-carbon agricultural innovation diffusion has been confirmed, there are 
very limited literatures on the diffusion of low-carbon agricultural technology innovation from the perspective of the dynamic system [16]. Different from the existing literature, we analyze the diffusion of low-carbon agricultural innovation based on evolutionary game theory. We consider the roles of key stakeholders in the process of low-carbon agricultural innovation diffusion, analyze the relationship between agricultural enterprises, farmers, and the government, explore the causes of the slow diffusion of low-carbon agricultural innovation, and reveal the evolutionary mechanism of low-carbon agricultural innovation diffusion. On the basis of theoretical analysis, the complexity scientific method was introduced and the evolutionary game model of low-carbon agricultural innovation diffusion was established $[17,18]$. Then, we use the numerical simulation method to examine the dynamic evolution path of the game system and to analyze the impact of low-carbon policies on the behavior of agricultural enterprises, government, and farmers. This paper explains two issues that are not fully addressed in the previous literature. First, what is the diffusion mechanism of low-carbon agricultural technology through agricultural enterprises and farmers? Second, how does the government's low-carbon policy affect the diffusion of low-carbon agricultural innovation? Based on the findings, the paper provides recommendations for low-carbon scholars and policymakers.

The remainder of this paper is organized as follows. Section 2 reviews the literature related to low-carbon agricultural innovation diffusion. Section 3 describes these problems in the diffusion of low-carbon agricultural technology, puts forward the theoretical hypothesis of the model, and provides the parameters and variables of the model. Section 4 establishes a trilateral evolutionary game theory model of the interaction among agricultural enterprises, government, and farmers and assesses the stability of the model. Section 5 describes the results of evolutionary game simulation. Section 6 presents the conclusion and some policy suggestions.

\section{Literature Review}

2.1. Obstacles to the Diffusion of Low-Carbon Agricultural Innovation. Rogers first put forward the theory of innovation diffusion [19]. He defines innovation diffusion as a process in which innovation can spread over time among members of the social system through certain channels. Innovative technology will affect economic and social development only when it is diffused and widely applied [20]. Since the theory is proposed, it has attracted significant scholarly attention in the past decades [21, 22].

In recent years, this theory has also attracted the attention of agriculturists and environmentalist. Mannan et al. believed that innovative attributes play an active role in the promotion and adoption of green fertilizer technology in rice cultivation in Malaysia [23]. High-input agriculture not only increases greenhouse gas emissions but also causes huge economic losses and environmental damage in many countries [24]. For example, excessive use of nitrogen fertilizer has resulted in excessive nitrate in groundwater and surface water, which has a negative impact on human health [25]. The management of aquatic ecosystems with excessive nitrates will cost a lot of money [26]. It is generally accepted that the use of low-carbon technology in agriculture is of great significance to agricultural progress. Reducing carbon in agriculture and improving soil nutrients and productivity of agroecosystems through the use of organic fertilizers and low-carbon technologies are crucial for developing sustainable, low-carbon, and climate-adaptive agriculture $[27,28]$.

However, there are great obstacles on the development and popularization of low-carbon agricultural technology. From the perspective of farmers, individual characteristics, family characteristics, information channels, and psychological characteristics are considered to be important factors affecting farmers' low-carbon behavior $[9,29,30]$. On the one hand, the adoption of low-carbon technology requires capital investment, and insufficient funds are an important factor restricting farmers to adopt low-carbon technology [31]. On the other hand, farmers' enthusiasm for using lowcarbon technologies is low due to lack of awareness or knowledge [7]. Furthermore, time and learning costs required to use new technologies also reduce the adoption of low-carbon technologies by farmers to a certain extent $[8,9,32]$. From the perspective of agricultural enterprises, due to the long cycle, high cost, and high risk of low-carbon technology innovation, the low-carbon innovation enthusiasm of agricultural enterprises is not high [11]. Therefore, the development of low-carbon agricultural technology cannot be separated from the support of government policies [10].

2.2. The Impact of Low-Carbon Policy on the Diffusion of Agricultural Low-Carbon Innovation. The theory of market failure has occupied a central position in public policy research [33]. According to the theory, the pursuit of private interests will lead to inefficient outcomes due to monopoly, externality, and information asymmetry [34]. Therefore, the government intervention is needed to solve these problems. Freibauer et al. showed that increasing the organic input of cultivated land, encouraging farmers to grow organic crops, and strengthening the government's low-carbon policy can improve the carbon sequestration function of the agricultural land [35]. Adzawla et al. indicated that the adoption of agricultural technologies can increase production while reducing greenhouse gas emissions. Therefore, in addition to greenhouse gas reduction initiatives or climate stabilization policies, carbon tax policies should be deemed as a strategic choice to promote the diffusion of low-carbon technologies [36]. Innovation subsidy for emission reduction is an effective measure to achieve food security and reduce agricultural pollution in China [37]. Qiao et al. found that government subsidy has a significant positive effect on the low-carbon agricultural technology adoption [38]. However, Liu et al. believed that the current economic incentives have not greatly improved the adoption rate of sustainable agricultural practices at the farm level, and technical training for farmers can increase the likelihood of low-carbon 
agricultural technology adoption [13]. Some scholars suggested that farmers are the main body of the diffusion of lowcarbon agricultural innovation, so it is more important to change farmers' views on environmental issues and climate change $[7,32]$. Lybbert and Sumner argued that national and international policymakers must incorporate a global perspective into agricultural policies in order to better address global climate change. From innovation to technology transfer and access to agricultural innovation technologies for small farmers in developing countries, agricultural policies play an important role at all levels [6].

\subsection{Application of Evolutionary Game in Low-Carbon In-} novation Diffusion. As an analytical tool, game theory has been applied to various fields of research studies to explain social phenomena [39-42]. Evolutionary game theory originated as an application of game theory to evolving populations of life forms in biology. The evolutionary game model based on the bounded rationality assumption might have more realistic significance than the game theory model based on the complete rational assumption. In recent years, the application of evolutionary game theory in the field of low-carbon economy has been increasing. For example, Mahmoudi and Rasti-Barzoki established the evolutionary game models between government and enterprise and analyzed the impact of government policies on enterprise behavior [43]. Zhang et al. examined the impact of lowcarbon policies on green technology diffusion in enterprise alliances [44].Wang and Zheng studied low-carbon diffusion from the perspective of network characteristics and consumer environmental awareness [45]. Fan and Dong established an evolutionary game model between enterprises and consumers and discussed the impact of government subsidy policies on the diffusion of new energy vehicles [46].

As can be seen from the abovementioned literature review, the evolutionary game model has been applied to the study of low-carbon diffusion, but the related research mainly focuses on the industrial sector and pays less attention to the agricultural sector [47]. Prior studies mainly considered the relationship between government and manufacturing enterprises or between consumers and manufacturing enterprises. However, few scholars analyzed the diffusion of low-carbon agricultural innovation from the perspective of multistakeholder relationship. It is difficult to see the application of evolutionary game in low-carbon agriculture [15].

\section{Problem Description and Assumptions}

3.1. Problem Description. The process of diffusion of lowcarbon agriculture innovation is also the process of adoption of low-carbon agricultural technology. This is a long process, which requires the joint efforts of agricultural enterprises, farmers, and the government $[12,15]$. The government is the promoter and beneficiary of innovation diffusion in lowcarbon agriculture. The government can promote low-carbon innovation of agricultural enterprises and encourage farmers to adopt low-carbon technology through the implementation of policy tools such as low-carbon subsidies and tax rebates [14].

Agricultural enterprises that provide low-carbon agricultural means of production and technical services are the main body of low-carbon agricultural technology innovation. Agricultural production materials mainly include agricultural machinery and equipment, semimechanized agricultural tools, small and medium-sized agricultural tools, pesticides, fertilizers, and agricultural plastic film. Low-carbon innovation of agricultural enterprises is to improve the energy efficiency of resource utilization of agricultural enterprises and achieve effective management of all aspects of agricultural production through the $R \& D$ of energy-saving technologies, waste recycling technologies, and biotechnology [48-51]. Due to the high cost, long cycle, high risk, and uncertain benefits of agricultural low-carbon technology R\&D, the innovation enthusiasm of agricultural enterprises is not high [13]. Agricultural enterprises avoid risks and seek to maximize their own interests. There is great uncertainty about whether agricultural enterprises choose low-carbon innovation strategy. Therefore, effective government policies need to be formulated and implemented in order to guide and standardize the low-carbon innovation of the agricultural enterprises.

Farmers are users of low-carbon agricultural technologies. Farmers' adoption of low-carbon innovative technologies is essential for promoting the development of low-carbon agriculture [52-56]. For the farmers, the main determinant of low-carbon technology adoption is the profitability and feasibility of greenhouse gas emission reduction measures. In particular, the early use of low-carbon agricultural technology may not bring about a rapid increase in farmers' income, but a decline in farmers' output and income [47]. At the same time, due to farmers' lack of awareness of low-carbon agriculture and the high cost of barriers to adopting low-carbon agricultural technology, the diffusion of low-carbon agricultural technology is facing greater resistance from farmers [7-9]. Thus, it is more important for the government to increase publicity on lowcarbon agriculture and compensate for the decline in farmers' income by subsidizing the adopters of low-carbon agricultural technologies. In addition, while providing lowcarbon technology and products to farmers, agricultural enterprises are required to provide corresponding technical services to farmers.

In short, the government, agricultural enterprises, and farmers are the main stakeholders in the process of lowcarbon agricultural innovation diffusion [15]. These stakeholders are all bounded rationality. They choose their own behavioral strategies from the perspective of maximizing their own interests, thus forming a complex game relationship. This will be a long-term and complex game process.

3.2. Model Assumptions. We assume that the strategies of agricultural enterprises are $\{$ Low-carbon innovation, Not low-carbon innovation\}. The strategies of government are \{Regulation, Not regulation\}, while the strategies of farmers are \{Adoption, Not adoption\}. $x, y$, and $z$ represent the 
probability of agricultural enterprises' choice of low-carbon innovation, government regulation, and farmers' adoption low-carbon technology, respectively. Correspondingly, $1-$ $x, 1-y$, and $1-z$ represent that the probability that agricultural enterprises do not choose low-carbon innovation, that the government does not regulate, and that farmers do not adopt low-carbon technology, respectively.

$H_{1}$ represents the benefit obtained by the agricultural enterprises, when they do not choose low-carbon innovation strategies. $\Delta h_{11}$ and $\Delta h_{12}$, respectively, represents the benefit increase that the agricultural enterprises can obtain through low-carbon innovation, when the government chooses the "Regulate" strategies and the "Not regulation" strategies. $C_{1}$ represents the cost of agricultural enterprises when they choose low-carbon innovation strategy.

$\mathrm{H}_{2}$ represents the social benefit obtained by the government, when the enterprises do not choose low-carbon innovation. Under the case of enterprises choosing lowcarbon innovations, $\Delta h_{21}$ and $\Delta h_{22}$, respectively, represent the benefit increase of the government, when the government adopts the "Regulate" strategies and the "Not regulation" strategies.

$\mathrm{H}_{3}$ represents the utility obtained by the farmers, when they do not adopt low-carbon technology. $\Delta h_{3}$ represents the utility increase of the farmers, when they adopt low-carbon technology. When agricultural enterprises select "Low-carbon innovation" strategies, the farmers can gain $w$ the social effect, regardless of whether they adopt low-carbon technology.

In the case of government regulation, the amount of innovation subsidies for the agricultural enterprises is $\alpha C_{1}$, when the agricultural enterprises choose low-carbon innovate strategies. The government levies $\beta F$ carbon tax on agricultural enterprises, when the agricultural enterprises do not choose low-carbon innovation strategies. The amount of adoption subsidies for the farmers is $\gamma C_{3}$, when the farmers adopt low-carbon technology. According to the actual situation in economies, we suppose that $\Delta h_{11}>\Delta h_{12}$, $\Delta h_{21}>\Delta h_{22}$, and $0 \leq \alpha, \beta, \gamma \leq 1$. The corresponding parameters are shown in Table 1 .

According to the abovementioned analysis, the payoff matrix among agricultural enterprises, government, and farmers is established, as shown in Table 2 .

\section{The Evolutionary Game Model Solution and Analysis}

4.1. The Replicated Dynamic Equation. Let $U_{\mathrm{e} 1}$ and $U_{\mathrm{e} 2}$ represent, respectively, the expected earnings of "Low-carbon innovation" and "Not low-carbon innovation" for agricultural enterprises. According to the payoff matrix, the fitness of agricultural enterprises with two different strategies can be calculated as follows:

$$
\begin{aligned}
& U_{\mathrm{e} 1}=H_{1}-C_{1}+\Delta h_{12} z+\alpha C_{1} y+\left(\Delta h_{11}-\Delta h_{12}\right) y z, \\
& U_{\mathrm{e} 2}=H_{1}-\beta F y .
\end{aligned}
$$

The average expected earnings of agricultural enterprises can be calculated as

$$
\bar{U}_{\mathrm{e}}=x U_{\mathrm{e} 1}+(1-x) U_{\mathrm{e} 2} .
$$

The replication dynamics equation for agricultural enterprises can be achieved as follows:

$$
\begin{aligned}
F(x)= & x(1-x)\left(U_{\mathrm{e} 1}-U_{\mathrm{e} 2}\right)=x(1-x)\left(\left(\alpha C_{1}+\beta F\right) y\right. \\
& \left.+\Delta h_{12} z+\left(\Delta h_{11}-\Delta h_{12}\right) y z-C_{1}\right) .
\end{aligned}
$$

Similarly, the expected earnings of "Regulation" and "Not regulation" for government can be calculated as follows:

$$
\begin{aligned}
& U_{\mathrm{g} 1}=H_{2}+\beta F+\left(\Delta h_{21}-\alpha C_{1}-\beta F\right) x-\gamma C_{3} z, \\
& U_{\mathrm{g} 2}=H_{2}+\Delta h_{22} x .
\end{aligned}
$$

The average expected earnings of government can be calculated as

$$
\bar{U}_{\mathrm{g}}=y U_{\mathrm{g} 1}+(1-y) U_{\mathrm{g} 2} .
$$

The replication dynamics equation for the government can be achieved as follows:

$$
\begin{aligned}
F(y)= & y(1-y)\left(U_{\mathrm{g} 1}-U_{\mathrm{g} 2}\right)=y(1-y)\left(\beta F+\left(\Delta h_{21}-\Delta h_{22}\right.\right. \\
& \left.\left.-\alpha C_{1}-\beta F\right) x-\gamma C_{3} z\right) .
\end{aligned}
$$

The expected earnings of "Adoption" and "Not adoption" for farmers can be calculated as follows:

$$
\begin{aligned}
& U_{\mathrm{c} 1}=H_{3}+\Delta h_{3}-C_{3}+w x+\gamma C_{3} y, \\
& U_{\mathrm{c} 2}=H_{3}+w x .
\end{aligned}
$$

The average expected earnings of farmers can be calculated as

$$
\bar{U}_{\mathrm{c}}=z U_{\mathrm{c} 1}+(1-z) U_{\mathrm{c} 2} .
$$

The replication dynamics equation for farmers can be achieved as follows:

$F(z)=z(1-z)\left(U_{\mathrm{c} 1}-U_{\mathrm{c} 2}\right)=z(1-z)\left(\Delta h_{3}-C_{3}+\gamma C_{3} y\right)$.

The replication dynamics equation of each stakeholder has the following form:

$$
\left\{\begin{array}{l}
F(x)=x(1-x)\left(\left(\alpha C_{1}+\beta F\right) y+\Delta h_{12} z+\left(\Delta h_{11}-\Delta h_{12}\right) y z-C_{1}\right), \\
F(y)=y(1-y)\left(\beta F+\left(\Delta h_{21}-\Delta h_{22}-\alpha C_{1}-\beta F\right) x-\gamma C_{3} z\right), \\
F(z)=z(1-z)\left(\Delta h_{3}-C_{3}+\gamma C_{3} y\right) .
\end{array}\right.
$$

4.2. Model Analysis. To seek the system's stable strategy, let the replicated dynamic equation of agricultural enterprises, government, and farmers be zero, that is, $F(x)=0$, $F(y)=0$, and $F(z)=0$. According to the evolutionary game theory, we obtain nine local equilibrium points of replicated dynamic equation: $U_{1}(1,1,1), U_{2}(1,1,0)$, $U_{3}(1,0,1), U_{4}(0,1,1), U_{5}(1,0,0), U_{6}(0,1,0), U_{7}(0,0,1)$, 
TABle 1: Parameter descriptions.

\begin{tabular}{|c|c|c|}
\hline Stakeholders & Parameters & Descriptions \\
\hline \multirow{6}{*}{$\begin{array}{l}\text { Agricultural } \\
\text { enterprises }\end{array}$} & $x$ & The probability that agricultural enterprises carry out low-carbon innovation \\
\hline & $H_{1}$ & The benefits when agricultural enterprises do not carry out low-carbon innovation \\
\hline & $\Delta h_{11}$ & $\begin{array}{c}\text { The benefit increase when the government chooses "regulation" strategies and the farmers adopt low- } \\
\text { carbon technology }\end{array}$ \\
\hline & $\Delta h_{12}$ & The benefit increase when the government choose "not regulation" strategies and the farmers adopt \\
\hline & $\Delta n_{12}$ & low-carbon technology \\
\hline & $C_{1}$ & The costs increase when agricultural enterprises carry out low-carbon innovation \\
\hline \multirow{8}{*}{ Government } & $y$ & The probability that government regulates low-carbon innovation \\
\hline & $\mathrm{H}_{2}$ & The social benefit when the agricultural enterprises adopt general innovation \\
\hline & $\Delta h_{21}$ & $\begin{array}{c}\text { The benefit increase when the government adopts "regulation" strategies and the agricultural } \\
\text { enterprises carry out low-carbon innovation }\end{array}$ \\
\hline & $\Delta h_{22}$ & $\begin{array}{c}\text { The benefit increase when the government does not regulate and the agricultural enterprises adopt low- } \\
\text { carbon innovation }\end{array}$ \\
\hline & $F$ & $\begin{array}{c}\text { The amount of carbon taxes levied on agricultural enterprises adopting "not low-carbon innovation" } \\
\text { strategies }\end{array}$ \\
\hline & $\alpha$ & The ratio of innovation subsidies to agricultural enterprises' low-carbon innovation input cost \\
\hline & $\beta$ & Carbon tax rate \\
\hline & $\gamma$ & The ratio of adoption subsidies to farmers' low-carbon technology purchase cost \\
\hline \multirow{5}{*}{ Farmers } & $z$ & The probability that farmers adopt low-carbon technology \\
\hline & $H_{3}$ & The benefits when farmers do not adopt low-carbon technology \\
\hline & $\Delta h_{3}$ & The increase benefits when farmers adopt low-carbon technology \\
\hline & $C_{3}$ & The costs increase when farmers adopt low-carbon technology \\
\hline & $w$ & $\begin{array}{l}\text { The benefits increase when agricultural enterprises carry out low-carbon innovation, regardless of } \\
\text { whether farmers adopt low-carbon technology }\end{array}$ \\
\hline
\end{tabular}

TABLE 2: The payoff matrix among agricultural enterprises, government, and farmers.

\begin{tabular}{|c|c|c|c|}
\hline \multirow{2}{*}{ Agricultural enterprises } & \multirow{2}{*}{ Government } & \multicolumn{2}{|c|}{ Farmers } \\
\hline & & Adoption $(z)$ & Not adoption $(1-z)$ \\
\hline Low-carbon innovation $(x)$ & $\begin{array}{c}\text { Regulation }(y) \\
\text { Not regulation }(1-y)\end{array}$ & $\begin{array}{c}H_{1}+\Delta h_{11}-(1-\alpha) C_{1} \\
H_{2}+\Delta h_{21}-\alpha C_{1}-\gamma C_{3} \\
H_{3}+w-\Delta h_{3}-(1-\gamma) C_{3} \\
H_{1}+\Delta h_{12}-C_{1} \\
H_{2}+\Delta h_{22} \\
H_{3}+w-\Delta h_{3}-C_{3}\end{array}$ & $\begin{array}{c}H_{1}-(1-\alpha) C_{1} \\
H_{2}+\Delta h_{21}-\alpha C_{1} \\
H_{3}+w \\
H_{1}-C_{1} \\
H_{2}+\Delta h_{22} \\
H_{3}+w\end{array}$ \\
\hline Not low-carbon innovation $(1-x)$ & $\begin{array}{c}\text { Regulation }(y) \\
\text { Not regulation }(1-y)\end{array}$ & $\begin{array}{c}H_{1}-\beta F \\
H_{2}+\beta F-\gamma C_{3} \\
H_{3}+\Delta h_{3}-(1-\gamma) C_{3} \\
H_{1} \\
H_{2} \\
H_{3}+\Delta h_{3}-C_{3}\end{array}$ & $\begin{array}{c}H_{1}-\beta F \\
H_{2}+\beta F \\
H_{3} \\
H_{1} \\
H_{2} \\
H_{3}\end{array}$ \\
\hline
\end{tabular}

$U_{8}(0,0,0)$, and $U_{9}\left(x^{*}, y^{*}, z^{*}\right) . U_{9}\left(x^{*}, y^{*}, z^{*}\right)$ is the solution of

$$
\left\{\begin{array}{l}
\left(\alpha C_{1}+\beta F\right) y+\Delta h_{12} z+\left(\Delta h_{11}-\Delta h_{12}\right) y z-C_{1}=0 \\
\beta F+\left(\Delta h_{21}-\Delta h_{22}-\alpha C_{1}-\beta F\right) x-\gamma C_{3} z=0, \\
\Delta h_{3}-C_{3}+\gamma C_{3} y=0 .
\end{array}\right.
$$

The equilibrium points are not necessarily the evolutionary stable strategies (ESS). According to research by
Friedman [53], the stability of the equilibrium points can be judged from the Jacobin matrix. The Jacobin matrix of replication dynamics equation and its eigenvalues are as follows:

$$
J=\left[\begin{array}{lll}
F_{11} & F_{12} & F_{13} \\
F_{21} & F_{22} & F_{23} \\
F_{31} & F_{32} & F_{33}
\end{array}\right]
$$

where 


$$
\begin{aligned}
F_{11}= & \frac{\partial A(x)}{\partial x}=(1-2 x)\left(\left(\alpha C_{1}+\beta F\right) y+\Delta h_{12} z\right. \\
& \left.+\left(\Delta h_{11}-\Delta h_{12}\right) y z-C_{1}\right) \\
F_{12}= & \frac{\partial A(x)}{\partial y}=x(1-x)\left(\alpha C_{1}+\beta F+\left(\Delta h_{11}-\Delta h_{12}\right) z\right), \\
F_{13}= & \frac{\partial A(x)}{\partial z}=x(1-x)\left(\Delta h_{12}+\left(\Delta h_{11}-\Delta h_{12}\right) y\right), \\
F_{21}= & \frac{\partial B(y)}{\partial x}=\left(\Delta h_{21}-\Delta h_{22}-\alpha C_{1}-\beta F\right) y(1-y), \\
F_{22}= & \frac{\partial B(y)}{\partial y}=(1-2 y)\left(\beta F+\left(\Delta h_{21}-\Delta h_{22}-\alpha C_{1}-\beta F\right)\right. \\
& \left.\cdot x-\gamma C_{3} z\right), \\
F_{33}= & \frac{\partial C(z)}{\partial z}=(1-2 z)\left(\Delta h_{3}-C_{3}+\gamma C_{3} y\right) \\
F_{23}= & \frac{\partial B(y)}{\partial z}=-\gamma C_{3} y(1-y), \\
F_{31}= & \frac{\partial C(z)}{\partial x}=0, \\
F_{32}= & \frac{\partial C(z)}{\partial y}=\gamma C_{3} z(1-z), \\
&
\end{aligned}
$$

According to Lyapunov's indirect method, the equilibrium point is an evolutionary stable strategy (ESS), when $F_{11}, F_{22}$, and $F_{33}$ are negative; the equilibrium point is an unstable point, when $F_{11}, F_{22}$, and $F_{33}$ are positive; the equilibrium point is a saddle point, when there are one or two positive numbers in $F_{11}, F_{22}$, and $F_{33}$. We only consider the equilibrium points $U_{1}$ to $U_{8}$ because the equilibrium resolution of three-party evolutionary game is a strict Nash equilibrium. The main eigenvalues of the Jacobian matrix at different equilibrium points are shown in Table 3.

Since $C_{1}>0$ and $\beta F>0$, the equilibrium points $(1,0,0)$ and $(0,0,0)$ may be a saddle point or an unstable point. The equilibrium points $(1,1,1),(1,1,0),(1,0,1),(0,1,1),(0,1,0)$, and $(0,0,1)$ may be the potential evolutionary stability strategies of the three-party game model. Among these potential stabilization strategies, the strategies that agricultural enterprises carry out low-carbon innovation and farmers adopt low-carbon technology are ideal stabilization strategies. Therefore, we only discuss the equilibrium points $(1,0,1)$ and $(1,1,1)$.

The equilibrium point $(1,0,1)$ is the ESS, when $\Delta h_{12}-C_{1}>0, \Delta h_{21}-\Delta h_{22}-\alpha C_{1}-\gamma C_{3}<0$, and $\Delta h_{3}-C_{3}$ $>0$. The equilibrium point $(1,0,1)$ is an unstable point, when $\Delta h_{12}-C_{1}<0, \Delta h_{21}-\Delta h_{22}-\alpha C_{1}-\gamma C_{3}>0$, and $\Delta h_{3}-C_{3}<0$. And the equilibrium point $(1,0,1)$ is a saddle point, when $C_{1}-\Delta h_{12}, \Delta h_{21}-\Delta h_{22}-\alpha C_{1}-\gamma C_{3}$, and $C_{3}-$
$\Delta h_{3}$ have one or two positive numbers. Under the conditions of government nonregulation, the agricultural enterprises adopt low-carbon innovation strategy, when their earnings of nonlow-carbon innovation are less than those of lowcarbon innovation. The government chooses "Not regulation" strategy, when its regulatory benefit is less than the onregulatory benefit. The farmers select "Adoption" strategy, when their benefits of adopting low-carbon technology are higher than the benefits of adopting nonlow-carbon technology. Combined with the current social reality, the social benefits of the government adopting "Regulation" strategy must be greater than the gains from the choice of "Not regulation" strategy. Therefore, we will not consider this situation in depth.

The equilibrium point $U_{8}(1,1,1)$ is also analyzed with this method. When $\left(\Delta h_{11}+\beta F-(1-\alpha) C_{1}\right)>0, \Delta h_{21}-$ $\Delta h_{22}-\alpha C_{1}-\gamma C_{3}>0$, and $\Delta h_{3}-(1-\gamma) C_{3}>0$, the equilibrium point $(1,1,1)$ is the ESS. When $\left(\Delta h_{11}+\beta F-\right.$ $\left.(1-\alpha) C_{1}\right)<0, \quad \Delta h_{21}-\Delta h_{22}-\alpha C_{1}-\gamma C_{3}<0, \quad$ and $\Delta h_{3}-$ $(1-\gamma) C_{3}<0$, the equilibrium point $(1,1,1)$ is an unstable point. When $\Delta h_{3}-(1-\gamma) C_{3}<0, \Delta h_{21}-\Delta h_{22}-\alpha C_{1}-\gamma C_{3}$, and $\Delta h_{3}-(1-\gamma) C_{3}$ have one or two positive numbers, the equilibrium point $(1,1,1)$ is a saddle point. The results indicate that the agricultural enterprises adopt low-carbon innovation strategy, when its earnings of nonlow-carbon innovation is less than that of low-carbon innovation; the government accept "Regulation" strategy, when its regulatory benefit is higher than the nonregulatory benefit; the farmers choose "Adoption" strategy, when their benefits adopting low-carbon technology is larger than the benefits adopting nonlow-carbon technology.

\section{Simulation Analysis}

The numerical simulations are carried out using Matlab software. We only discuss the equilibrium point $(1,1,1)$ and consider the effect of initial strategy selection and influence factors on evolution results. According to Section 4, when $\left(\Delta h_{11}+\beta F-(1-\alpha) C_{1}\right)>0, \quad \Delta h_{21}-\Delta h_{22}-\alpha C_{1}-\gamma C_{3}>0$, and $\Delta h_{3}-(1-\gamma) C_{3}>0$, the system finally achieves to the ideal state, that is, the ESS is the strategy set $\{$ Low-carbon innovation, Regulation, Adoption $\}$. We set $\Delta h_{11}=6$, $\Delta h_{21}=5, \Delta h_{22}=2, \Delta h_{12}=5, \Delta h_{3}=0.8, C_{1}=4, C_{3}=0.5$, $F=1, \alpha=0.3, \beta=0.2, \gamma=0.3$, and $\omega=0.1$. The time is set to $t=20$.

5.1. Effect of Initial Strategy Selection. When the initial value of the strategy combination $(x, y, z)$ is set as $U_{0}=(0.5,0.5,0.5)$, the strategy selection results of stakeholders are shown in Figure 1. From the two-dimensional and three-dimensional simulation diagrams, we can find that the probabilities of participants choosing strategy 1 increase with time. Ultimately, the agricultural enterprises choose "Low-carbon innovation" strategy, the government chooses "Regulation" strategy, and the farmers choose "Adoption" strategy, and thus reaching ESS point $U_{1}=(1,1,1)$. 
TABLE 3: Main eigenvalues of the Jacobian matrix.

\begin{tabular}{cccc}
\hline$x, y, z$ & $F_{11}$ & $F_{22}$ & $F_{33}$ \\
\hline $1,1,1$ & $-\left(\Delta h_{11}+\beta F-(1-\alpha) C_{1}\right)$ & $-\left(\Delta h_{21}-\Delta h_{22}-\alpha C_{1}-\gamma C_{3}\right)$ & $-\left(\Delta h_{3}-(1-\gamma) C_{3}\right)$ \\
$1,1,0$ & $-\left(\beta F-(1-\alpha) C_{1}\right)$ & $-\left(\Delta h_{21}-\Delta h_{22}-\alpha C_{1}\right)$ & $\Delta h_{3}-(1-\gamma) C_{3}$ \\
$1,0,1$ & $-\left(\Delta h_{12}-C_{1}\right)$ & $\Delta h_{21}-\Delta h_{22}-\alpha C_{1}-\gamma C_{3}$ & $-\left(\Delta h_{3}-C_{3}\right)$ \\
$0,1,1$ & $\Delta h_{11}+\beta F-(1-\alpha) C_{1}$ & $-\left(\beta F-\gamma C_{3}\right)$ & $-\left(\Delta h_{3}-(1-\gamma) C_{3}\right)$ \\
$1,0,0$ & $C_{1}$ & $\Delta h_{21}-\Delta h_{22}-\alpha C_{1}$ & $\Delta h_{3}-C_{3}$ \\
$0,1,0$ & $\beta F-(1-\alpha) C_{1}$ & $-\beta F$ & $\Delta h_{3}-(1-\gamma) C_{3}$ \\
$0,0,1$ & $\Delta h_{12}-C_{1}$ & $\beta F-\gamma C_{3}$ & $-\left(\Delta h_{3}-C_{3}\right)$ \\
$0,0,0$ & $-C_{1}$ & $\beta F$ & $\Delta h_{3}-C_{3}$ \\
\hline
\end{tabular}

Note: $F_{12}=F_{13}=F_{21}=F_{23}=F_{31}=F_{32}=0$.

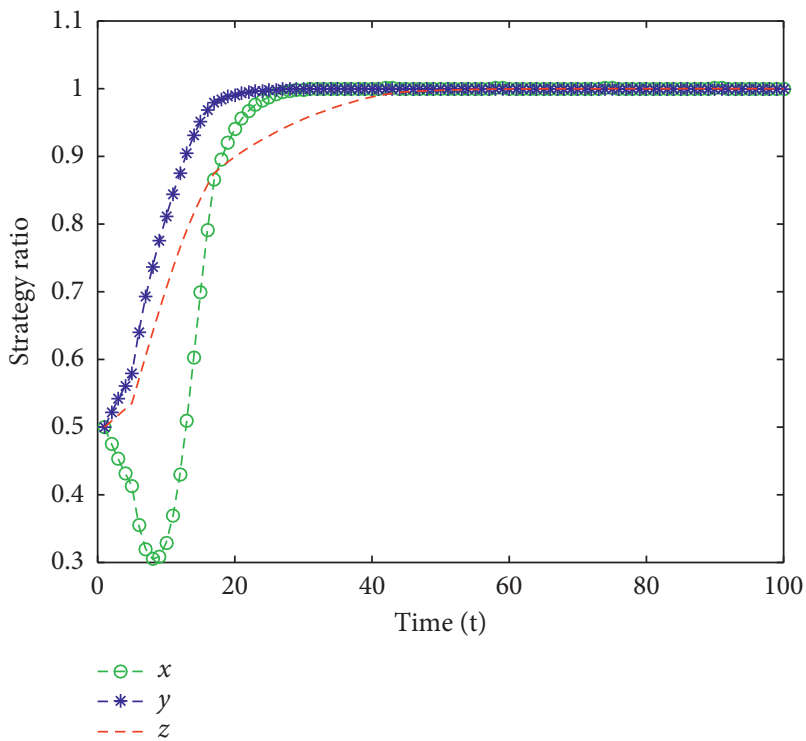

(a)

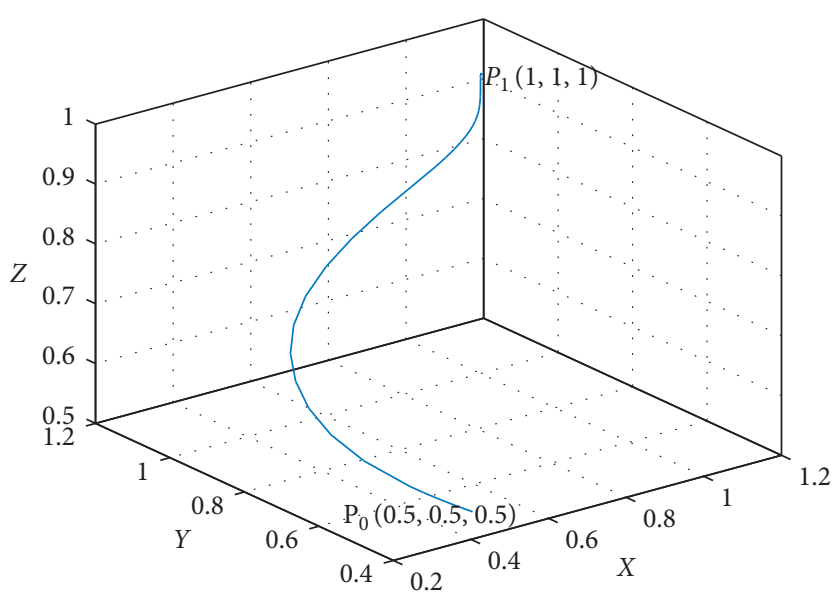

(b)

Figure 1: The dynamic evolution of the tripartite game model when $x=0.5, y=0.5$, and $z=0.5$. (a) Time evolutions of $x, y$, and $z$; (b) time evolutions of $(x, y, z)$.

\subsection{Effect of Government Behavior on the Strategy Selection.} Government subsidies to agricultural enterprises and farmers, as well as government carbon tax requirements for nonlow-carbon innovative enterprises, may have an effect on the strategy choices of agricultural enterprises and farmers. We discuss the influence of the abovementioned factors on the evolutionary results.

\subsubsection{Innovation Subsidies for Agricultural Enterprises.} In order to examine the impact of innovation subsidies for agricultural enterprises, we set the parameter $\alpha$ in the interval $[0,1]$, while fixing the value of the other parameters. The simulation results shown in Figure 2 suggest that when the ratio of innovation subsidies to agricultural enterprises' low-carbon innovation input cost increase from 0.1 to 0.9 , the "Low-carbon innovation" strategy ratio of agricultural enterprises and the "Adoption" strategy ratio of farmers will increase, but the "Regulation" strategy ratio of government will decrease. The results of simulation coincide with the explanation that market failure is the fundamental reason for the government to subsidize low-carbon innovation activities, which creates a gap between private interests and social interests [33]. The government can obtain more societal benefits through supporting firms' innovation. However, the government will select "Not regulation" strategy, when the amount of government subsidies is greater than the social benefits obtained by the government. From abovementioned analysis, we can see that government subsidies may have a substitution effect in the initial stage and reduce the enthusiasm of low-carbon innovation of agricultural enterprises, but with the passage of time it will play an incentive role and promote low-carbon innovation of agricultural enterprises. At the same time, innovation subsidies have an incentive effect on farmers to adopt low-carbon technologies. However, if the amount of financial subsidies is too large, it will affect the enthusiasm of government subsidies.

5.2.2. Carbon Taxes for Agricultural Enterprises. Carbon tax policy is an important measure to reduce carbon emissions $[54,55]$. In order to examine the effect of the carbon tax rate, 


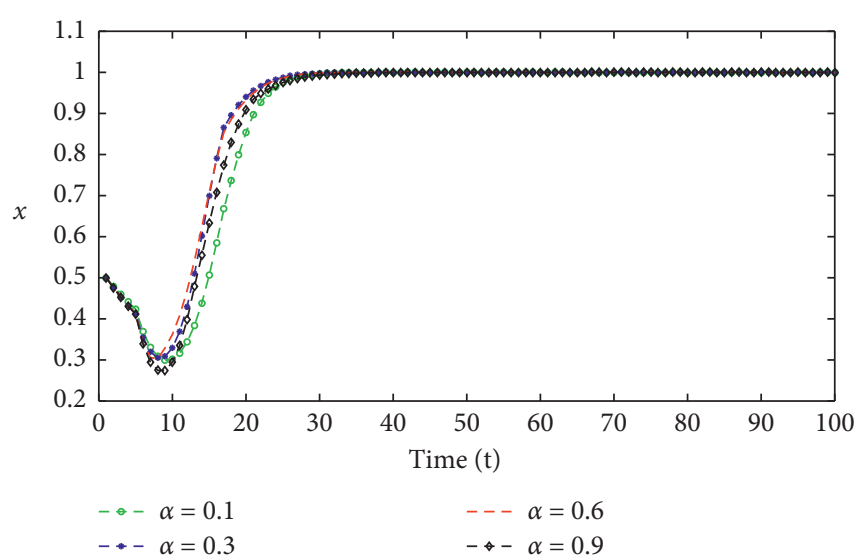

(a)

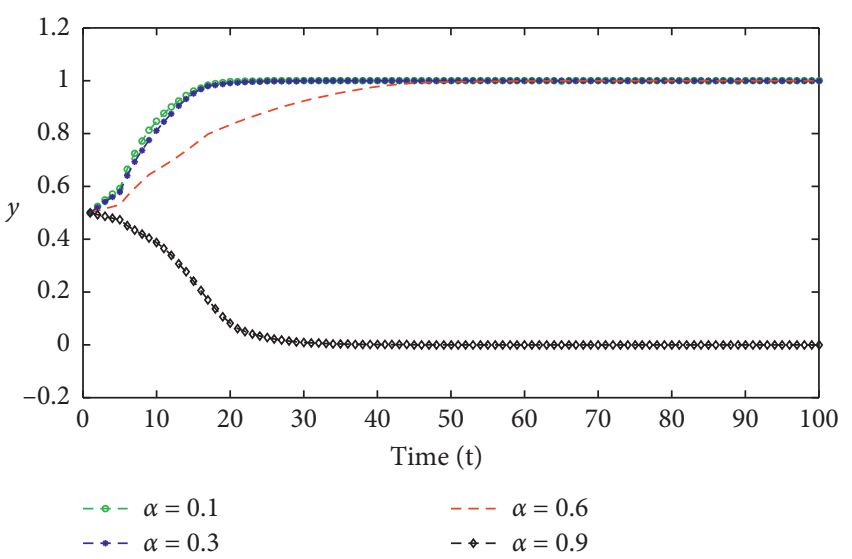

(b)

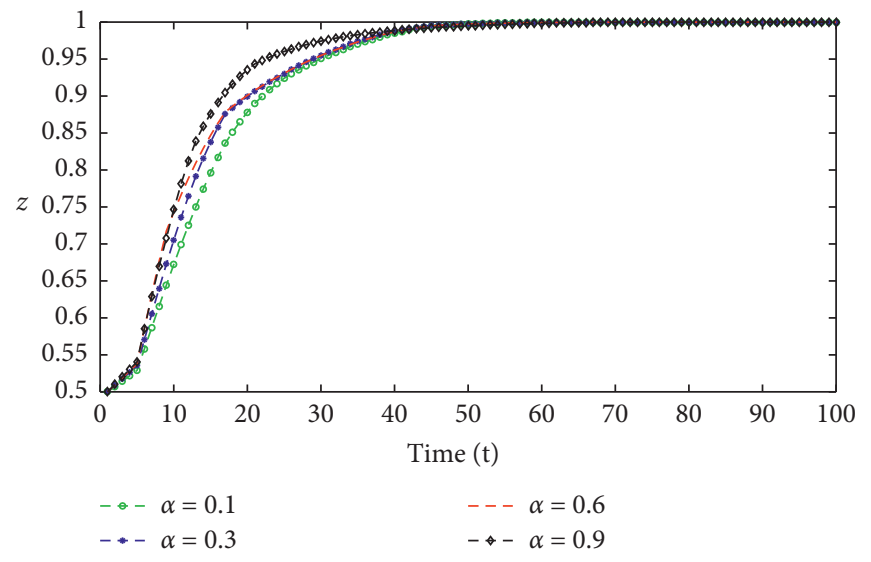

(c)

Figure 2: The effect of innovation subsidies on the evolutionary strategies.

we set the parameter $\beta$ in the interval $[0,1]$, while fixing the other parameters. The results shown in Figure 3 indicate that when the carbon tax rate increases from 0.1 to 0.9 , the "Lowcarbon" strategy ratio of agricultural enterprises and the "Regulation" strategy ratio of government increase, while the "Adoption" strategy ratio of farmers decreases. The results suggest that the higher the carbon tax rate, the higher the willingness of agricultural enterprises to carry out lowcarbon innovation and the higher the probability of government choosing regulatory strategies. However, the increase of the carbon tax has a negative impact on farmers' adoption of low-carbon technology. The reason may be that, on the one hand, the increase of the carbon tax has led to the decrease in the supply of nonlow-carbon technology and the increase in the price of nonlow-carbon technology. The inertia of farmers in choosing agricultural technology has stimulated the increase of market demand for nonlowcarbon technology. On the other hand, the farmers do not have sufficient awareness of the importance of the environment, and the diffusion of low-carbon agricultural technology will take longer. Therefore, it is difficult to improve the speed and scope of agricultural low-carbon technology in the short term by relying solely on the carbon tax policy. Carbon tax policy needs are combined with other low-carbon policy tools to promote the popularization of low-carbon technology in agriculture.

5.2.3. Adoption Subsidies for Farmers. In order to examine the effect of adoption subsidies for farmers, we set the parameter $\gamma$ in the interval $[0,1]$, while keeping all other parameters constant. The simulation results shown in Figure 4 indicate that the ratio of government subsidies to farmers' low-carbon product purchase cost increases from 0.1 to 0.9 , the "Low-carbon innovation" strategy ratio of agricultural enterprises and the "Adoption" strategy ratio of farmers increase, while the "Regulation" strategy ratio of government decrease. The results indicate that government subsidies increase farmers' enthusiasm for adopting lowcarbon technology. The more subsidies farmers receive, the higher is their demand for low-carbon technology products and the higher is the enthusiasm of agricultural enterprises for low-carbon innovation. Similar to the analysis of government subsidies for agricultural enterprises, the larger the 


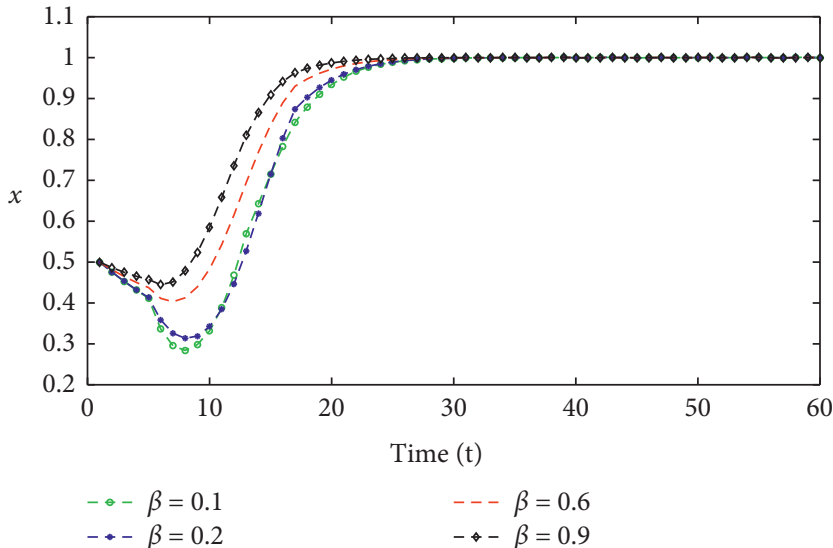

(a)

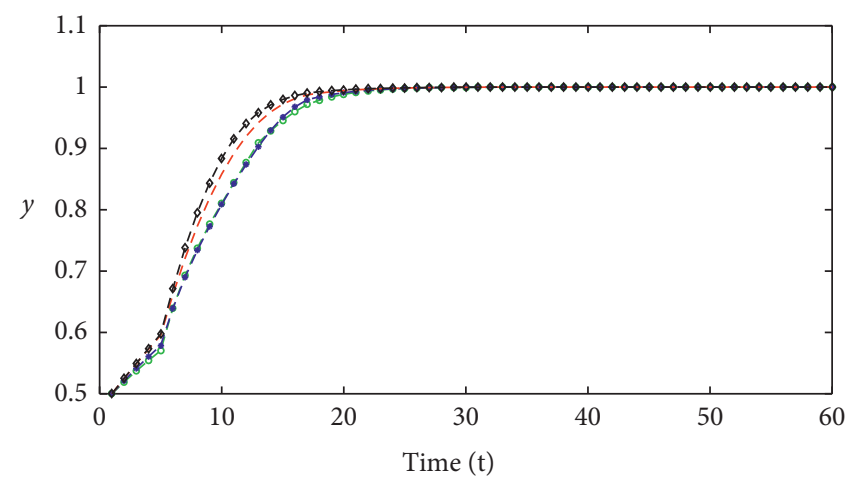

$-\beta=0.1$

$\cdots \beta=0.2$

$--\beta=0.6$

$-\rightarrow-\beta=0.9$

(b)

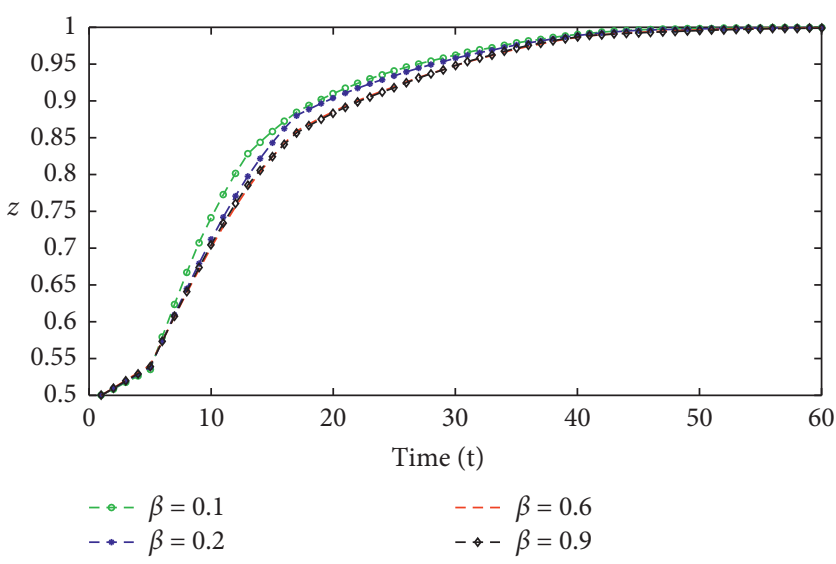

(c)

Figure 3: The effect of the carbon tax rate on the evolutionary strategies.

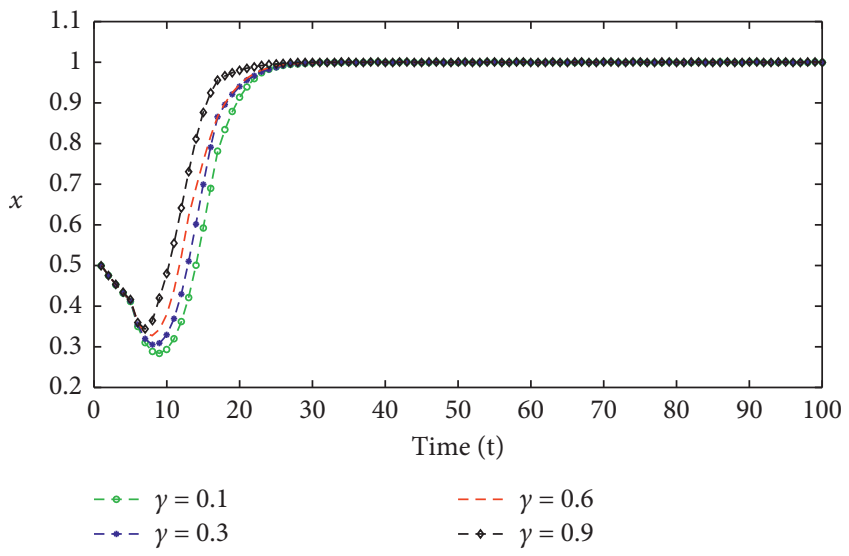

(a)

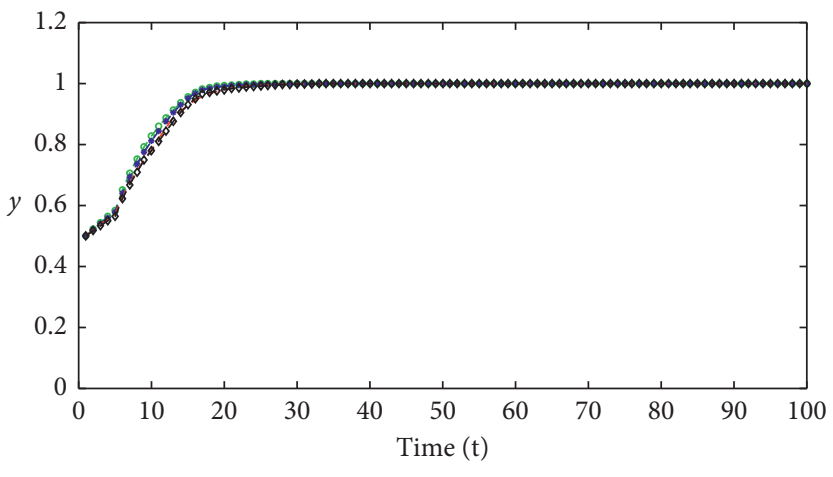

$-\gamma=0.1$

$\cdots-\gamma=0.3$

$--\gamma=0.6$

$-\rightarrow-\gamma=0.9$

(b)

Figure 4: Continued. 


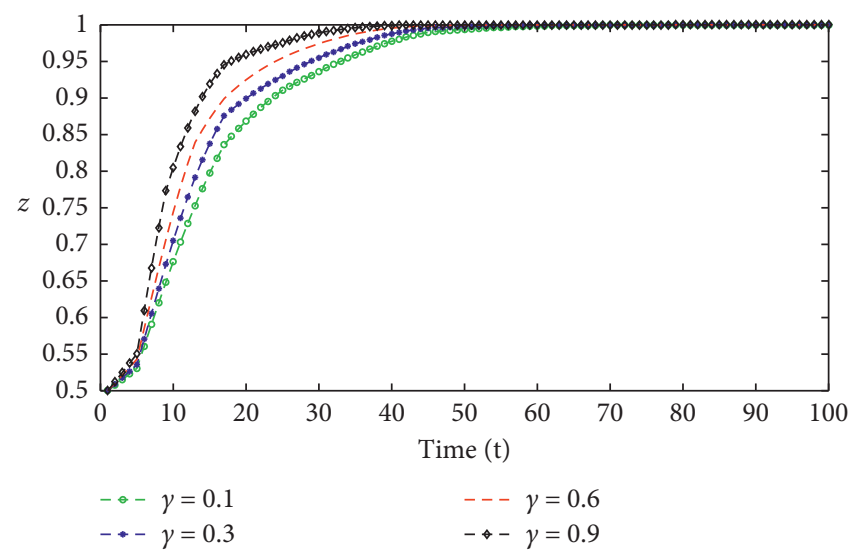

(c)

FIGURE 4: The effect of adoption subsidies on the evolutionary strategies.

amount of adoption subsidies is, the lower the enthusiasm of government subsidies is.

\section{Conclusions and Suggestions}

Developing low-carbon agriculture is an inevitable choice to reduce greenhouse gas emissions, improve agricultural ecological environment, and realize agricultural modernization. The innovation and diffusion of low-carbon agricultural technologies cannot be separated from the participation of relevant stakeholders such as agricultural enterprises, government, farmers, and intermediaries. However, current research on the interrelationship of multiple stakeholders in low-carbon agricultural technology innovation and diffusion is very limited. Different from previous studies, this paper establishes a tripartite game model involving agricultural enterprises, government, and farmers using evolutionary game theory. Then, simulation analysis based on MATLAB software is implemented to explore the impact of government policies on the innovation diffusion of low-carbon agriculture. The results show that

(1) The cost of low-carbon innovation, the increased revenue from low-carbon innovation, and government regulation (including carbon taxes and innovation subsidies) are the main factors affecting the low-carbon innovation of agricultural enterprises.

(2) Low-carbon production costs, additional benefits from low-carbon production, and adoption subsidies for low-carbon are the principal factors affecting farmers' adoption of low-carbon technologies.

(3) The probability of government regulation is mainly affected by the cost and benefit of low-carbon regulation, which decreases with the increase of regulation costs and increases with the increase of regulatory benefits.

(4) Government subsidies for low-carbon innovation, carbon taxes, and government subsidies for lowcarbon technology adoption are effective means to promote the diffusion of low-carbon technologies in agriculture. High-level of innovation subsidies and adoption subsidies inspires the enthusiasm of agricultural enterprises for low-carbon innovation and farmers for low-carbon technology adoption. The high level of carbon taxes arouses the enthusiasm of low-carbon innovation of agricultural enterprises. However, it inhibits farmers' adoption of low-carbon technologies in the short term.

This study contributes to the present literature on innovation diffusion theory in two areas. First, evolutionary game theory is utilized to study the diffusion of low-carbon agricultural innovation based on multiple stakeholders. The reduction of agricultural greenhouse gas emissions depends not only on farmers' low-carbon production but also on the innovation of low-carbon agricultural technology. It is significance to reveal the mechanism of the interaction between agricultural enterprises and farmers in low-carbon agricultural innovation diffusion. This study compensates for the current lack of application of innovation diffusion theory in agriculture [47]. Second, the effects of low-carbon policy instruments (innovation subsidies, carbon taxes, and adoption subsidies) on low-carbon agricultural technology innovation diffusion are studied, which is of great value in the formulation and implementation low-carbon agricultural policies.

This study also has policy implications. First, the government should increase the propaganda of the importance of low-carbon agriculture and low-carbon agriculture policies through training, meetings, and public service advertisements and strengthen the awareness of agricultural enterprises and farmers to low-carbon agriculture. In order to reduce the cost of government regulation, the public, media, and nongovernmental organizations should be fully mobilized to participate in the production regulation of agricultural enterprises. Second, the appropriate subsidy level should be committed to prevent agricultural enterprises and farmers from defrauding low-carbon subsidies caused by excessive subsidies. This policy can be combined with other policies such as carbon trading market to avoid marketing problems caused by insufficient supply of 
nonlow-carbon production materials in the short term. Third, a communication platform should be built for agricultural enterprises, scientific research institutions, farmers, and financial institutions, which can promote the R\&D and industrialization of low-carbon agricultural technologies. The farmers can get the latest market information of lowcarbon agricultural technologies and choose the applicable low-carbon agricultural technology.

\section{Data Availability}

The data used to support the findings of this study are available from the corresponding author upon request.

\section{Conflicts of Interest}

The authors declare no conflicts of interest regarding the publication of this paper.

\section{Authors' Contributions}

All authors have read and approved the final manuscript.

\section{Acknowledgments}

This paper was supported by the Tianjin Planning Leading Group Office of Philosophy and Social Sciences under Grant no. TJYY17-017.

\section{References}

[1] T. F. Stocker, D. Qin, G. K. Plattner, M. Tignor, and S. K. Allen, "Intergovernmental panel on climate changeIPCC: climate change 2013: the physical science basis," Contribution of Working Group I to the Fifth Assessment Report of IPCC. Chapter: Summary for Policymakers, Cambridge University Press, Cambridge, UK, 2013.

[2] Z. Wang, X. Deng, Y. Bai, J. Chen, and W. Zheng, "Land use structure and emission intensity at regional scale: a case study at the middle reach of the Heihe River basin," Applied Energy, vol. 183, pp. 1581-1593, 2016.

[3] P. Smith, D. Martino, Z. Cai, D. Gwary, and H. Janzen, "Greenhouse gas mitigation in agriculture," Philosophical Transactions of the Royal Society B: Biological Sciences, vol. 363, no. 1492, pp. 789-813, 2008.

[4] D. Nayak, E. Saetnan, K. Cheng et al., "Management opportunities to mitigate greenhouse gas emissions from Chinese agriculture," Agriculture, Ecosystems \& Environment, vol. 209, pp. 108-124, 2015.

[5] Y. Qi, H. M. Li, and X. Wang, "Agriculture and low-carbon development strategy in China," Scientia Agricultura Sinica, vol. 45, no. 1, pp. 1-6, 2012.

[6] T. J. Lybbert and D. A. Sumner, "Agricultural technologies for climate change in developing countries: policy options for innovation and technology diffusion," Food Policy, vol. 37, no. 1, pp. 114-123, 2012.

[7] J. Deng, P. Sun, F. Zhao, X. Han, G. Yang, and Y. Feng, "Analysis of the ecological conservation behavior of farmers in payment for ecosystem service programs in eco-environmentally fragile areas using social psychology models," Science of the Total Environment, vol. 550, pp. 382-390, 2016.

[8] J. Huang, R. Hu, J. Cao, and S. Rozelle, "Training programs and in-the-field guidance to reduce China's overuse of fertilizer without hurting profitability," Journal of Soil and Water Conservation, vol. 63, no. 5, pp. 165A-167A, 2008.

[9] D. Pan, F. Kong, N. Zhang, and R. Ying, "Knowledge training and the change of fertilizer use intensity: evidence from wheat farmers in China," Journal of Environmental Management, vol. 197, pp. 130-139, 2017.

[10] A. P. Barnes and L. Toma, "A typology of dairy farmer perceptions towards climate change," Climatic Change, vol. 112, no. 2, pp. 507-522, 2012.

[11] N. Adnan, S. M. Nordin, M. A. Bahruddin, and A. H. Tareq, "A state-of-the-art review on facilitating sustainable agriculture through green fertilizer technology adoption: assessing farmers behavior," Trends in Food Science \& Technology, vol. 86, pp. 439-452, 2019.

[12] J. K. Harper, G. W. Roth, B. Garalejić, and N. Š.and, "Programs to promote adoption of conservation tillage: a Serbian case study," Land Use Policy, vol. 78, pp. 295-302, 2018.

[13] Y. Liu, J. Ruiz-Menjivar, L. Zhang, J. Zhang, and M. E. Swisher, “Technical training and rice farmers' adoption of low-carbon management practices: the case of soil testing and formulated fertilization technologies in Hubei, China," Journal of Cleaner Production, vol. 226, pp. 454-462, 2019.

[14] T. Garnett, "Where are the best opportunities for reducing greenhouse gas emissions in the food system (including the food chain)?" Food Policy, vol. 36, pp. S23-S32, 2011.

[15] X. He, W. Tang, and Y. Peng, "Evolutionary game analysis of respective stakeholders during promotion process of lowcarbon agriculture," Journal of Northwest A\&F University, vol. 16, no. 1, pp. 59-65, 2016.

[16] Y. Zhou, M. Pan, D. K. Zhou, and L. Xue, "Stakeholder risk and trust perceptions in the diffusion of green manufacturing technologies: evidence from China," The Journal of Environment \& Development, vol. 27, no. 1, pp. 46-73, 2017.

[17] J. Ma, L. Sun, S. Hou, and X. Zhan, "Complexity study on the Cournot-Bertrand mixed duopoly game model with market share preference," Chaos: An Interdisciplinary Journal of Nonlinear Science, vol. 28, no. 2, Article ID 023101, 2018.

[18] J. Ma, S. Hou, and B. Bao, "Short-term and long-term impacts of a quick response strategy on a dual channel apparel supply chain," International Journal of Bifurcation and Chaos, vol. 29, no. 14, Article ID 1950190, 28 pages, 2019.

[19] E. M. Rogers, Diffusion of Innovations, Free Press, New York, NY, USA, 5th edition, 2003.

[20] P. Stoneman, The Economic Analysis of Technological Chang, Oxford University Press, Oxford, UK, 1983.

[21] D. Corkal, W. C. Schutzman, and C. R. Hilliard, "Rural water safety from the source to the on-farm tap," Journal of Toxicology and Environmental Health Part A, vol. 67, no. 20-22, pp. 1619-1642, 2004.

[22] F. J. Carter, T. Jambulingam, V. K. Gupta, and N. Melone, "Technological innovations: a framework for communicating diffusion effects," Information \& Management, vol. 38, no. 5, pp. 277-287, 2011.

[23] S. Mannan, S. Nordin, S. Rafik-Galea, and A. R. Ahmad Rizal, "The ironies of new innovation and the sunset industry: diffusion and adoption," Journal of Rural Studies, vol. 55, pp. 316-322, 2017.

[24] J. Bruinsma, World Agriculture: Toward 2015/30-an FAO Perspective, FAO Rome and Earthscan, London, UK, 2003.

[25] L. Zhao, C. Wang, H. Gu, and C. Yue, "Market incentive, government regulation and the behavior of pesticide application of vegetable farmers in China," Food Control, vol. 85, pp. 308-317, 2018. 
[26] J. Li, P. Glibert, M. Zhou, S. Lu, and D. Lu, "Relationships between nitrogen and phosphorus forms and ratios and the development of dinoflagellate blooms in the East China Sea," Marine Ecology Progress Series, vol. 383, pp. 11-26, 2009.

[27] K. Meisterling, C. Samaras, and V. Schweizer, "Decisions to reduce greenhouse gases from agriculture and product transport: LCA case study of organic and conventional wheat," Journal of Cleaner Production, vol. 17, no. 2, pp. 222-230, 2009.

[28] Y. Bai, X. Deng, S. Jiang, Z. Zhao, and Y. Miao, "Relationship between climate change and low-carbon agricultural production: a case study in Hebei Province, China," Ecological Indicators, vol. 105, pp. 438-447, 2019.

[29] K.-C. Chang and Y. M. Seow, "Protective measures and security policy non-compliance intention," Journal of Organizational and End User Computing, vol. 31, no. 1, pp. 1-21, 2019.

[30] G. Khatwani and P. R. Srivastava, "Impact of information technology on information search channel selection for consumers," Journal of Organizational and End User Computing, vol. 30, no. 3, pp. 63-80, 2018.

[31] G. T. Abate, S. Rashid, C. Borzaga, and K. Getnet, "Rural finance and agricultural technology adoption in Ethiopia: does the institutional design of lending organizations matter?" World Development, vol. 84, pp. 235-253, 2016.

[32] C. R. Foguesatto, J. A. R. Borges, and J. A. D. Machado, "Farmers' typologies regarding environmental values and climate change: evidence from southern Brazil," Journal of Cleaner Production, vol. 232, pp. 400-407, 2019.

[33] D. Schmidtz, "Market failure," Critical Review, vol. 7, no. 4, pp. 525-537, 1993.

[34] J. Ma and H. Ren, "Influence of government regulation on the stability of dual-channel recycling model based on customer expectation," Nonlinear Dynamics, vol. 94, no. 3, pp. 17751790, 2018.

[35] A. Freibauer, M. D. A. Rounsevell, P. Smith, and J. Verhagen, "Carbon sequestration in the agricultural soils of Europe," Geoderma, vol. 122, no. 1, pp. 0-23, 2004.

[36] W. Adzawla, M. Sawaneh, and A. M. Yusuf, "Greenhouse gasses emission and economic growth nexus of sub-Saharan Africa," Scientific African, vol. 3, Article ID e00065, 2019.

[37] Y.-h. Chen, X.-w. Wen, B. Wang, and P.-y. Nie, "Agricultural pollution and regulation: how to subsidize agriculture?" Journal of Cleaner Production, vol. 164, pp. 258-264, 2017.

[38] J. Qiao, Y. Mu, X. Zhao, J. Zheng, and X. Qi, "The intervention effect of government subsidy on the adoption of low carbon agricultural technology in Shanxi and Hebei provinces," Journal of Arid Land Resources and Environment, vol. 30, no. 4, pp. 46-50, 2016.

[39] X. Su, H. Liu, and S. Hou, "The trilateral evolutionary game of agri-food quality in farmer-supermarket direct purchase: a simulation approach," Complexity, vol. 2018, no. 1, Article ID 5185497, 2018.

[40] L. Xie, J. Ma, and H. Han, "Implications of stochastic demand and manufacturers' operational mode on retailer's mixed bundling strategy and its complexity analysis," Applied Mathematical Modelling, vol. 55, pp. 484-501, 2018.

[41] X. Su, S. Duan, S. Guo, and H. Liu, "Evolutionary games in the agricultural product quality and safety information system: a multiagent simulation approach," Complexity, vol. 2018, Article ID 7684185, 13 pages, 2018.

[42] J. Ma and L. Sun, "Complexity analysis about nonlinear mixed Oligopolies game based on production cooperation," IEEE
Transactions on Control Systems Technology, vol. 26, no. 4, pp. 1532-1539, 2018.

[43] R. Mahmoudi and M. Rasti-Barzoki, "Sustainable supply chains under government intervention with a real-world case study: an evolutionary game theoretic approach," Computers \& Industrial Engineering, vol. 116, pp. 130-143, 2018.

[44] L. Zhang, L. Xue, and Y. Zhou, "How do low-carbon policies promote green diffusion among alliance-based firms in China? An evolutionary-game model of complex networks," Journal of Cleaner Production, vol. 210, pp. 518-529, 2019.

[45] L. Wang and J. Zheng, "Research on low-carbon diffusion considering the game among enterprises in the complex network context," Journal of Cleaner Production, vol. 210, pp. 1-11, 2019.

[46] R. Fan and L. Dong, "The dynamic analysis and simulation of government subsidy strategies in low-carbon diffusion considering the behavior of heterogeneous agents," Energy Policy, vol. 117, pp. 252-262, 2018.

[47] D. Norse, "Low carbon agriculture: objectives and policy pathways," Environmental Development, vol. 1, no. 1, pp. 25-39, 2012.

[48] E. J. Olguín, "Dual purpose microalgae-bacteria-based systems that treat wastewater and produce biodiesel and chemical products within a biorefinery," Biotechnology Advances, vol. 30, no. 5, pp. 1031-1046, 2012.

[49] C. Chen, J. Pan, and S. K. Lam, "A review of precision fertilization research," Environmental Earth Sciences, vol. 71, no. 9, pp. 4073-4080, 2014.

[50] J. Ma, X. Ma, and W. L. Ma, "Measure of the bullwhip effect considering the market competition between two retailers," International Journal of Production Research, vol. 55, no. 2, pp. 313-326, 2017.

[51] J. Ma and L. Xie, "The stability analysis of the dynamic pricing strategy for bundling goods: a comparison between simultaneous and sequential pricing mechanism," Nonlinear Dynamics, vol. 95, no. 2, pp. 1147-1164, 2019.

[52] M. N. Shahrina, M. S. Shamsuri, and M. N. Shuhaida, "Innovation diffusion of new technologies in the Malaysian paddy fertilizer industry," Procedia-Social and Behavioral Sciences, vol. 109, pp. 768-778, 2014.

[53] D. Friedman, "Evolutionary games in economics," Econometrica, vol. 59, no. 3, pp. 637-666, 1991.

[54] W. Lou and J. Ma, "Complexity of sales effort and carbon emission reduction effort in a two-parallel household appliance supply chain model," Applied Mathematical Modelling, vol. 64, pp. 398-425, 2018.

[55] W. Chen and Z.-H. Hu, "Using evolutionary game theory to study governments and manufacturers' behavioral strategies under various carbon taxes and subsidies," Journal of Cleaner Production, vol. 201, pp. 123-141, 2018.

[56] J. Ma, W. Lou, and Y. Tian, "Bullwhip effect and complexity analysis in a multi-channel supply chain considering price game with discount sensitivity," International Journal of Production Research, vol. 57, no. 17, pp. 5432-5452, 2019. 